\title{
Features of socialization and school adaptation of children with autism spectrum disorders
}

\author{
Yana Davydova ${ }^{1}$, Viktor Gorelik $^{1, *}$, Valery Vlasov $^{1}$, Irina Lazunina ${ }^{1}$, Natalia $_{\text {Nazarenko }}{ }^{1}$, \\ and Oksana Romenskaya ${ }^{1}$ \\ ${ }^{1}$ Togliatti State University, 14, Belorusskaya str., 445020, Togliatti, Russia
}

\begin{abstract}
The paper analyzes the theoretical foundations of social adaptation of children with autism spectrum disorders. Attention is focused on the widespread prevalence of autism not only in the Russian Federation, but also abroad, which makes the problem of social adaptation of children with autism spectrum disorders relevant today. The paper presents the data of a sociological survey on the problems of social adaptation and the organization of the educational process for children with autism. The paper reveals statistical indicators on the problems of autism in world practice and in the Russian Federation, focuses on disorders of the mental and psychological state, shows a deficit of emotional reactions, disturbances in the communicative sphere, and the lack of independence of children with autism. It is also noted that these children are immersed only in their own problems, not noticing the world around them.
\end{abstract}

\section{Introduction}

Data reflecting the prevalence of autism for 1966-2019 show a narrowing of the line between people with autism and the healthy population. This follows from an increase in the numbers reflecting the prevalence of this disease [4]. The American Centers for Disease Control and Prevention published an update in 2020, according to which one in 54 children has autism spectrum disorders, which is $10 \%$ more than in 2018. Autism is diagnosed in girls 4 times less often than in boys. It is also worth noting that African American boys under the age of 3 years are most susceptible to this disease, but autism spectrum disorders are found in all ethnic, racial and socioeconomic groups [5]. In the Russian Federation, according to the Federal State Statistics Service (Rosstat), the incidence of autism in children under the age of 14 (from 2014 to 2018) increased by $107.1 \%$ (from 5.3 to $11: 10,000$ ), among adolescents of $15-16$ years old (from 1.8 to $5.78: 10,000$ ) - by $206.4 \%$ [2]. Autism is a developmental disorder that is manifested by qualitative impairments in communication, social interaction, and a tendency to stereotypical behavior. Autism spectrum disorders are manifested in childhood and somehow persist throughout the entire life of a person [3].

According to the criteria adopted by the World Health Organization (WHO), with autism spectrum disorder, the following are noted:

- disturbances in social development;

*Corresponding author: lecgoy@list.ru 
- qualitative disturbances of the ability to communicate;

- limited interests, repetitive and stereotyped patterns of behavior and activities.

Because of their isolation, aggressiveness and profound disturbances in contact with the outside world, children with autism spectrum disorder are one of the most difficult to adapt groups. The consequence of these most pronounced manifestations is the extremely low possibility of adaptation of children to real life. A family raising a child with autism spectrum disorders is experiencing many difficulties and very limited in their capabilities. It is difficult for parents to choose an educational institution, since not all kindergartens and schools are adapted to work with children with autism spectrum disorder. Also, educational institutions do not have enough specially trained and experienced specialists, the large number of kids in groups and classes does not allow teachers to pay proper attention to "special" children. It is difficult for the family to go to public places, as the child's behavior can change and he will become aggressive at any time. The whole range of problems has a tremendous impact on the family's microsociety and the child's psyche, and also, to some extent, isolates him from the outside world.

In general, there are several main difficulties in social adaptation of children with autism spectrum disorders.

- difficulties in interacting with other people;

- inability to establish emotional connections;

- disturbances in the intellectual and mental spheres.

Social adaptation is the process of integrating a person into society, as a result of which the individual develops self-awareness and role behavior, forms the ability to self-service and interact with people around him.

For children with autism spectrum disorders, social adaptation represents specially organized actions and a continuous procedure for getting used to coexistence with the outside world through the assimilation of certain norms and rules [1].

\section{Problem Statement}

Obtaining affordable and high-quality education for children with autism spectrum disorders is one of the basic and essential conditions for their successful socialization. Legal guarantees of children with disabilities (autism) to receive education are enshrined in the following documents: the Constitution of the Russian Federation, in paragraph 10 of Article 50 of the Law of the Russian Federation "On Education", and Federal Laws "On Basic Guarantees of the Rights of the Child in the Russian Federation" dated 30 June 2007 No. 120-FZ, "On Social Protection of Disabled People in the Russian Federation", Federal Law of the Russian Federation of December 29, 2012 No. 273-FZ "On Education in the Russian Federation".

\section{Research Questions}

The socialization of children with autism is a multifaceted process of assimilating the experience of social life. Nowadays, in Russia, in addition to specialized correctional educational institutions, the process of integrating children with autism spectrum disorders into general educational institutions (in classes with children without developmental disabilities) is developing. It is possible to teach children with autism spectrum disorders according to an individual curriculum or program. It is extremely important to substantiate new approaches and create optimal conditions for the successful development of a child, his upbringing, training, social adaptation and integration into society. It is expedient and increasingly obvious to develop social assistance that fully meets the needs and 
requirements of both a child with autism spectrum disorders and his family as a whole. In connection with the above, we came to the conclusion that in order to solve the problems of social adaptation of children with autism spectrum disorders, it is necessary to develop a clearly organized set of measures for the interaction of educational institutions and social services that provide comprehensive assistance to the child and his relatives.

\section{Purpose of the Study}

Explore the current problems arising in the process of school adaptation and socialization of children with autism spectrum disorders.

\section{Research Methods}

1. Conduct a sociological study through questionnaires and identify problems that arise in children and their families in the process of school adaptation and socialization.

2. Develop a set of measures aimed at solving the problems identified by us.

3. Offer the set of measures developed by us for educational institutions, social services, as well as families with children with ASD.

The research methods included a set of general scientific methods: study and analysis of literature on the research problem, survey, questionnaire survey, pedagogical observation of students. Methods of mathematical processing were used in the analysis of empirical data. We conducted a sociological study in order to identify the problems of social adaptation of children with autism. The respondents were the parents of children with autism spectrum disorders (20 people) and the specialists of the State Budgetary Educational Institution of the boarding school No.2 in the Zhigulevsk urban district (15 experts). The survey of all respondents was carried out using the questionnaire method. Our research made it possible to identify the main problems associated with the social adaptation of children with autism and also to consider the following aspects:

- actual problems experienced by children with autism spectrum disorders;

- socially significant skills and abilities necessary for children with autism spectrum disorders for successful socialization and adaptation;

- problems of organizing the educational process of social adaptation of children with autism.

As a result of the questionnaire survey on the first block of questions, the most pressing problems, according to the respondents, are: aggressive behavior (38\%), complex relationships of children with autism spectrum disorders with others (26\%), social maladjustment (19\%) (Table 1), (Fig. 1).

Table 1. Actual problems of children with autism spectrum disorders.

\begin{tabular}{|l|c|}
\hline \multicolumn{1}{|c|}{ Problems } & $\%$ \\
\hline $\begin{array}{l}\text { Difficult relationships between children and } \\
\text { others }\end{array}$ & $26 \%$ \\
\hline Aggressive behavior & $38 \%$ \\
\hline Speech disorders & $3 \%$ \\
\hline Social maladjustment & $19 \%$ \\
\hline Behavioral problems & $7 \%$ \\
\hline School maladjustment & $5 \%$ \\
\hline Lack of independence & $2 \%$ \\
\hline
\end{tabular}




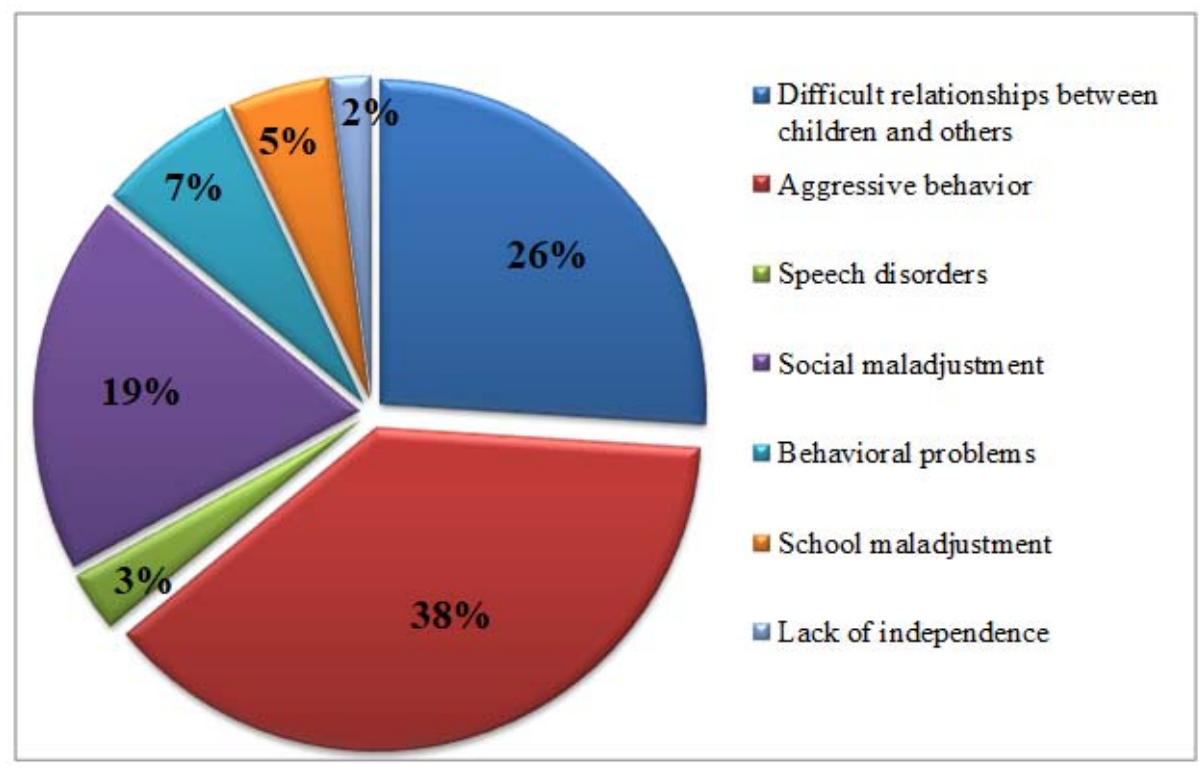

Fig. 1. Actual problems of children with autism spectrum disorders.

The second block of questions allowed us to find out the socially significant skills and abilities necessary for the successful social adaptation of children with ASD into society. We learned what skills and abilities, according to the respondents, should be formed in children within the walls of a boarding school (Figure 02).

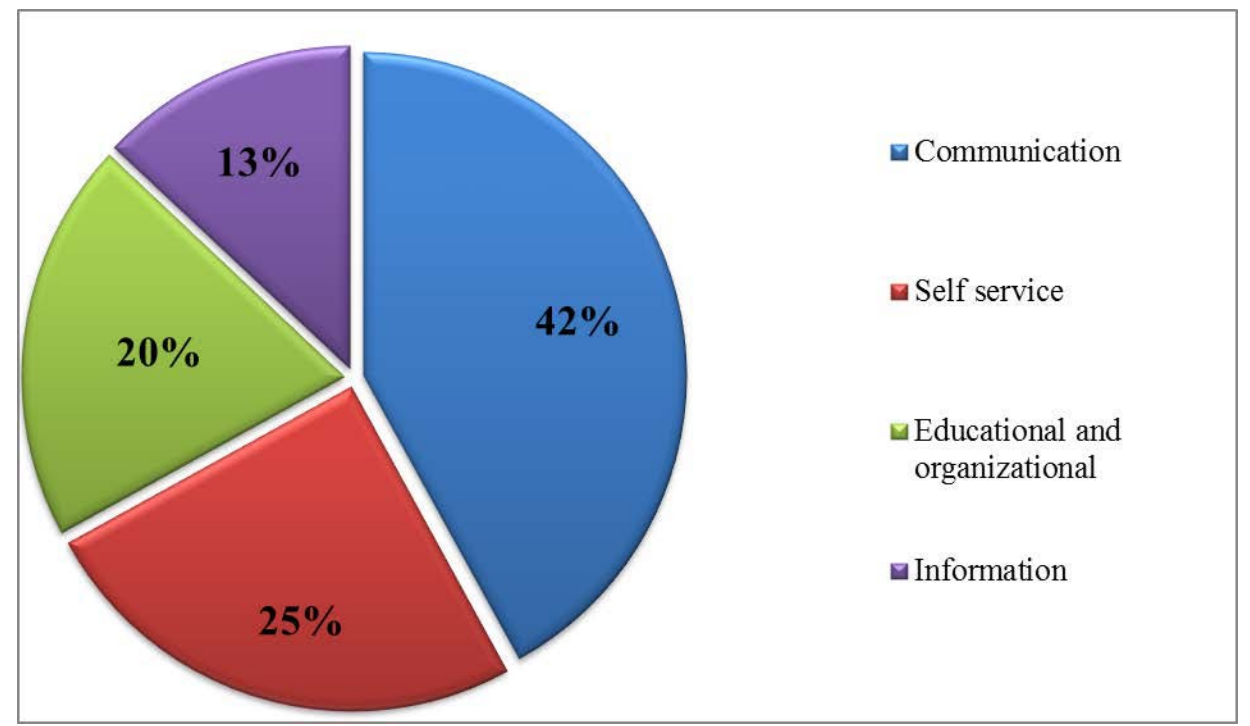

Fig. 2. Most important skills and abilities for children with autism in a boarding school.

According to the respondents, the most significant skills for the further independent life of children with autism are communication skills (42\%) and self-service skills $(25 \%)$. Answering the second block of questions, the overwhelming majority of respondents $(76 \%)$ also believe that children with autistic disorders do not have only some socially significant skills, the rest of the respondents are convinced that children do not have a significant 
number of skills and abilities (24\%) (Figure 03).

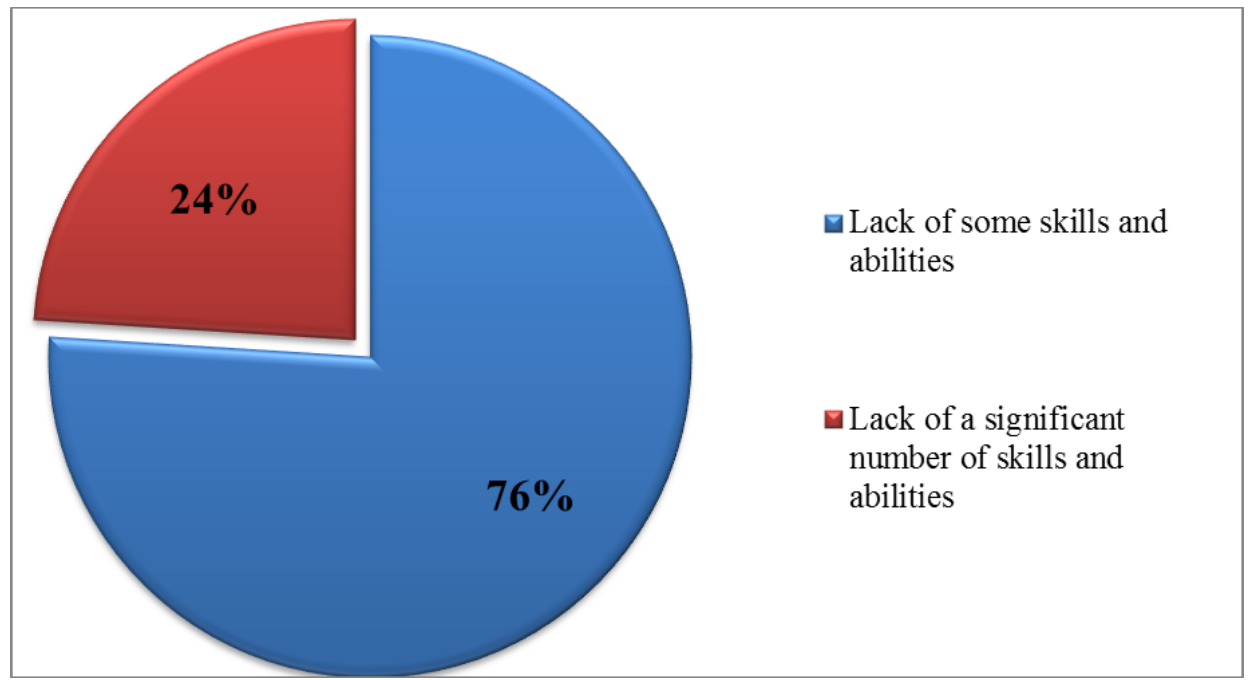

Fig. 3. Availability of socially significant skills and abilities.

The third block of questions allowed us to find out what difficulties families of children with ASD and boarding school specialists face in organizing the educational process (Figure 04).

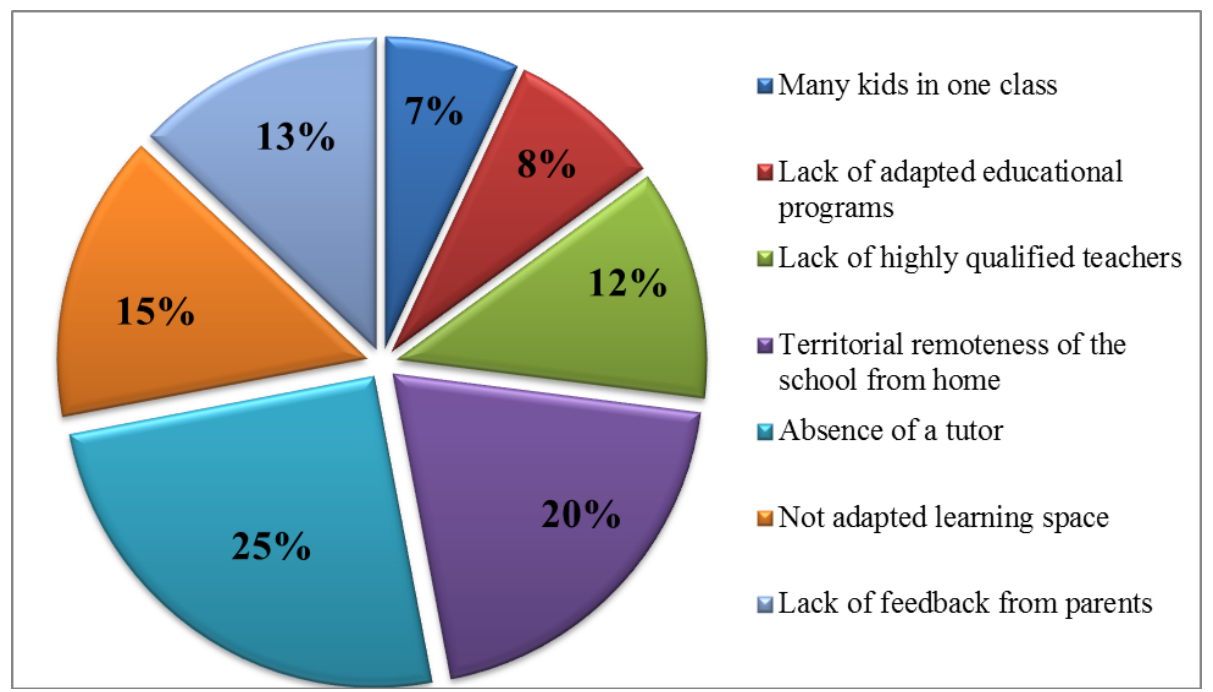

Fig. 4. Problems of organizing the educational process of social adaptation of children with autism.

According to the respondents, the most pressing problems that arise in organizing the educational process were the absence of a tutor $(27 \%)$, the territorial remoteness of the school from home $(21 \%)$, the lack of feedback from parents $(14 \%)$, as well as the lack of teachers trained for working with autistic children (13\%). After we developed and proposed a set of measures to improve the organization of social adaptation of children with autism studying at a boarding school, we conducted a survey, according to the results of which we found out that the majority of respondents (78\%) support our development and are ready to test it (Figure 05). 


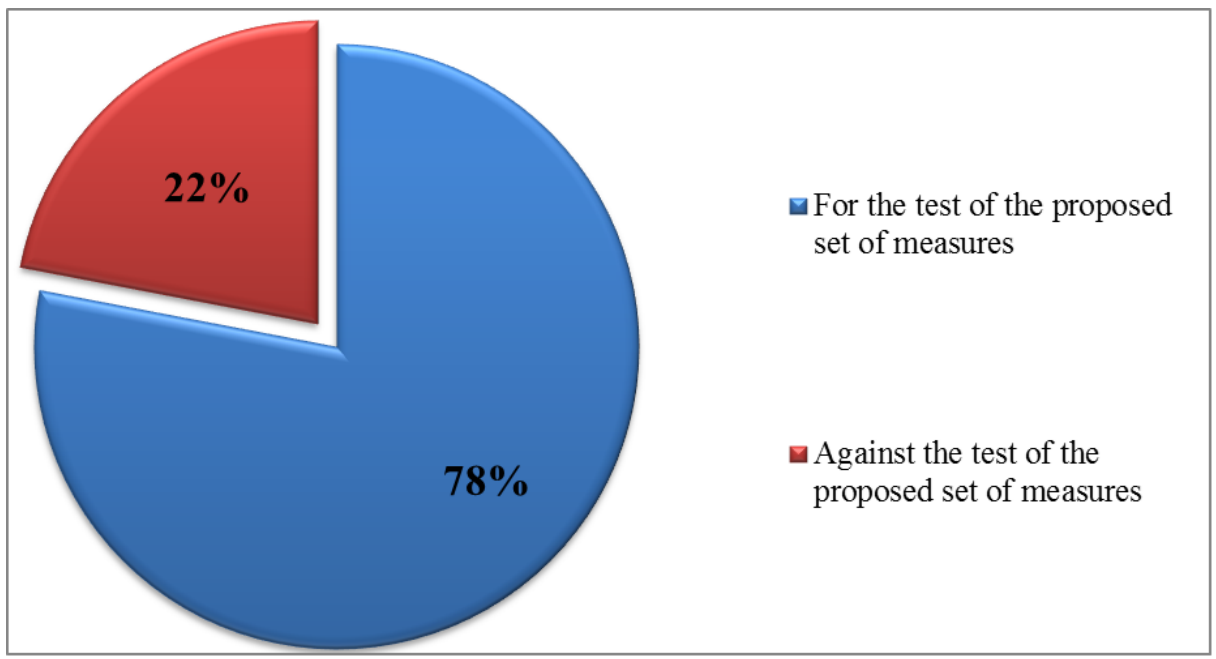

Fig. 5. Attitude towards testing the proposed set of measures to improve the organization of social adaptation of children with autism spectrum disorders.

Social adaptation of children with autism is a long and complex process, the links of which are primarily the child himself, his family, specialists of social, medical and educational services. Summing up, we can say that the creation of social adaptation of children with ASD proceeds in a complex form. This is caused by the totality of problems that must be solved by specialists from different structures and departments at different levels.

\section{Conclusions}

1. Our research by means of a questionnaire made it possible to identify the main problems that children with autism spectrum disorders experience in the process of school adaptation, as well as the most significant problems, according to the respondents, when organizing the educational process at a boarding school.

2. The set of measures proposed by us to improve the organization of social adaptation of children with autism was assessed positively by the majority of respondents.

\section{References}

1. I.Yu. Vetrova, Problems of social adaptation of disabled people (Delo, M., 2000)

2. E.V. Makushkin, N.K. Demcheva, Russian Journal of Psychiatry 4, 4-15 (2019)

3. L.M. Shipitsina, Childhood autism. Textbook for students of higher and secondary pedagogical, psychological and medical educational institutions (Didaktika Plus, SPb, 2006)

4. E. Rødgaard, K. Jensen, J. Vergnes et al., Journal of the American Medical Association. Psychiatry 76(11), 1124-1132 (2019)

5. Autism and Developmental Disorders Monitoring Network (ADDM), https://www.cdc.gov/ncbddd/autism/addm.html 